\title{
Erratum to: Corticosterone Induces Dysregulation of Iron Metabolism in Hippocampal Neurons In Vitro
}

\author{
Lei Wang • HuanYu Wang $\cdot \mathrm{Li} \mathrm{Li} \cdot$ Wei Li • \\ XiaoMan Dong $\cdot$ Min Li $\cdot \mathbf{L i ~ L v}$
}

Published online: 23 February 2010

(C) Springer Science+Business Media, LLC 2010

\section{Erratum to: Biol Trace Elem Res \\ DOI 10.1007/s12011-009-8565-9}

The original version of this article unfortunately contained two mistakes. (A) Dr. Min Li should be regarded as a co-corresponding author. And (B), we declare that this paper is funded by the National Natural Science Foundation of China (30872120).

The online version of the original article can be found at http://dx.doi.org/10.1007/s12011-009-8565-9.

L. Wang $\cdot$ H. Wang $\cdot$ L. Li $\cdot$ W. Li $\cdot$ X. Dong $\cdot$ L. Lv $(\bowtie)$

Department of Clinical Nutrition, General Hospital of Armed Police Forces, 69 Yongding Road, Beijing 100039, People's Republic of China

e-mail: crystalleilei@yahoo.com.cn

L. Wang

e-mail: crysta1800830@hotmail.com.cn

M. Li $(\bowtie)$

Department of Naval Medicine, Second Military Medical University, Shanghai 200433, China e-mail: linlimin115@hotmail.com 